\title{
Double-catheter lavage combined with percutaneous flexible endoscopic debridement for infected pancreatic necrosis failed to percutaneous catheter drainage
}

Pi Liu*, Jun Song, Hua-jing Ke, Nong-hua Lv, Yin Zhu, Hao Zeng, Yong Zhu, Liang Xia, Wen-hua He, Ji Li, Xin Huang and Yu-peng Lei

\begin{abstract}
Background: Infected pancreatic necrosis (IPN) is a serious local complication of acute pancreatitis, with high mortality. Minimally invasive therapy including percutaneous catheter drainage (PCD) has become the preferred method for IPN instead of traditional open necrosectomy. However, the efficacy of double-catheter lavage in combination with percutaneous flexible endoscopic debridement after PCD failure is unknown compared with surgical necrosectomy.

Methods: A total of 27 cases of IPN patients with failure PCD between Jan 2014 and Dec 2015 were enrolled in this retrospective cohort study. Fifteen patients received double-catheter lavage in combination with percutaneous flexible endoscopic debridement, and 12 patients underwent open necrosectomy. The primary endpoint was the composite end point of major complications or death. The secondary endpoint included mortality, major complication rate, ICU admission length of stay, and overall length of stay.

Results: The primary endpoint occurrence rate in double-catheter lavage in combination with percutaneous flexible endoscopic debridement group $(8 / 15,53 \%)$ was significantly lower than that in open necrosectomy group $(11 / 12,92 \%)(R R=1.71,95 \% \mathrm{Cl}=1.04-2.84, P<0.05)$. Though the mortality between two groups showed no statistical significance ( $0 \%$ vs. $17 \%, P=0.19)$, the rate of new-onset multiple organ failure and ICU admission length of stay in the experimental group was significantly lower than that in open necrosectomy group (13\% vs. $58 \%, P=0.04 ; 0$ vs. 17 , $P=0.02$, respectively). Only $40 \%$ of patients required ICU admission after percutaneous debridement, which was markedly lower than the patients who underwent surgery (83\%; $P<0.05)$.
\end{abstract}

Conclusions: Double-catheter lavage in combination with percutaneous flexible endoscopic debridement showed superior effectiveness, safety, and convenience in patients with IPN after PCD failure as compared to open necrosectomy.

Keywords: Infected pancreatic necrosis, Double-catheter lavage, Percutaneous flexible endoscopic debridement, Percutaneous catheter drainage, Open necrosectomy

\footnotetext{
* Correspondence: liupi1974@sina.com

Pi Liu, Jun Song and Hua-jing Ke contributed equally to this work.

Pi Liu, Jun Song and Hua-jing Ke are considered co-first authors.

Department of Gastroenterology, The First Affiliated Hospital of Nanchang

University, 17 Yongwaizheng Street, Nanchang, Jiangxi 330006, People's

Republic of China
} 


\section{Background}

Acute pancreatitis (AP) is a serious digestive system disease with a morbidity of 13-45/100,000 [1]. 10-20\% patients may develop pancreatic and peripancreatic necrosis, while $40-70 \%$ of patients with pancreatic necrosis develop asecondary infection [2]. Infected pancreatic necrosis (IPN)) is a severe local complication of AP with a mortality at about 30\% (12-39\%) [3-7]. The 2012 Atlanta classification define the local complications of acute pancreatits as acute peripancreatic fluid collection, pancreatic pseudocyst, acute necrotic collection (ANC), and walled-off necrosis (WON), which is classified into aseptic or infectious [8]. WON combined with infection is an important cause of death in the late stage of severe AP.

Open necrosectomy is the traditional treatment method for IPN, which may lead to further tissue damage and bleeding, and promote the inflammatory reaction, resulting in high complication rate (up to 95\%) and mortality ( 40\%) [9]. A variety of minimally invasive treatment options for IPN have emerged in the last decade, including percutaneous pigtail tube drainage, percutaneous $U$ tube drainage, double pigtail or metal stents drainage through the stomach, and minimally invasive Step-up approach, etc. Percutaneous pigtail tube drainage became the first-line treatment for IPN because of simple operation, convenience, and small disturbance to the patient. However, it was reported that the success rate of percutaneous drainage therapy for IPN was only $33 \%$ [10].

Van Santvoort et al. (2010) demonstrated that the minimally invasive step-up approach showed enhanced efficacy and safety in IPN as compared with open necrosectomy [11]. Although numerous reports suggest good efficacy of endoscopic ultrasonography in IPN treatment, video assisted retroperitoneal debridement or endoscopic transgastric necrosectomy requires significant technical expertise because of its complexity. To help further refine the treatment of this condition, this study evaluated the effectiveness and safety of percutaneous catheter drainage, followed by large aperture double catheter lavage combined with percutaneous flexible endoscopic debridement as compared with open necrosectomy.

\section{Methods}

\section{Clinical information}

A total of 1428 AP patients were admitted to our hospital, The First Affiliated Hospital of Nanchang University (Nanchang City, PRC), between Jan 1, 2014 and Dec 31, 2015, of which 75 patients were diagnosed as IPN. Twenty-eight patients who failed PCD were enrolled in the retrospective cohort study, one of which was excluded because he left against medical advice. The other 47 patients were excluded as follows: 15 patients improved rapidly with conservative management,16 patients improved after single PCD therapy, two patients died after a single $\mathrm{PCD}$, ten patients received drainage through the stomach combined with endoscopic ultrasonography (EUS), three patients bled after PCD and needed interventional or surgical therapy, and one patient was trauma-related (Fig. 1).

According to the 2012 Atlanta Acute Pancreatitis Classification, IPN diagnosis criteria included: (1) Contrastenhanced CT showed extraluminal gas in the pancreatic and/or peripancreatic tissue. (2) Percutaneous, imageguided, fine-needle aspiration (FNA) was positive for bacteria and/or fungi on Gram stain and culture [3]. Patients who were considered as PCD failures met the following criteria: (1) Clinical symptoms did not improve after more than 1 week of double catheter lavage and drainage as evidenced by fever, sepsis, and outflow obstruction, etc.; (2) a less than $75 \%$ reduction in collecs showed no statistical significantion size after 10 to 14 days' lavage and drainage [12]. Patients with the diagnosis of infected pancreatic necroses were enrolled after PCD failure.

Exclusion criteria included: (1) Patients with severe heart, lung, liver, or CNS disease, coagulopathies and other medical conditions that would preclude endoscopic or surgical treatment; (2). Pregnant or lactating women; (3) Drainage through the stomach; (4) Bleeding after PCD that required interventional or surgical treatment; (5) Refusal to sign the informed consent; (6) Discharge against medical advice; and (7) Patients who were trauma-related.

The trial was performed in a large pancreatitis center in the First Affiliated Hospital of Nanchang University, Jiangxi Province, China. The study was performed in accordance with the principles of the Declaration of Helsinki. The Medical Ethics Committee of the First Affiliated Hospital of Nanchang University approved the protocol(Ethical approval No. 2013020).All study participants gave informed consent. Written consent from patients was obtained for this study.

The patient demographics between the two groups showed no statistical significance regarding age, gender, BMI, pancreatic necrosis foci location, and severity, except pathogenesis proportion (Table 1).

\section{Double-catheter lavage in combination with percutaneous flexible endoscopic debridement treatment} All patients underwent percutaneous puncture by an $18 \mathrm{G}$ needle using the seldinger technique under the guidance of ultrasound or CT. A 8 to 14 French pigtail catheter was placed into the peripancreatic collection after the sinus tract was first expanded by a $8-14 \mathrm{Fr}$ dilator. A double catheter was placed 1 week later for continuous irrigation and drainage after the sinus tract was expanded using 14-30Fr dilators.(Double catheter is a self-designed large aperture tube, with many holes in 


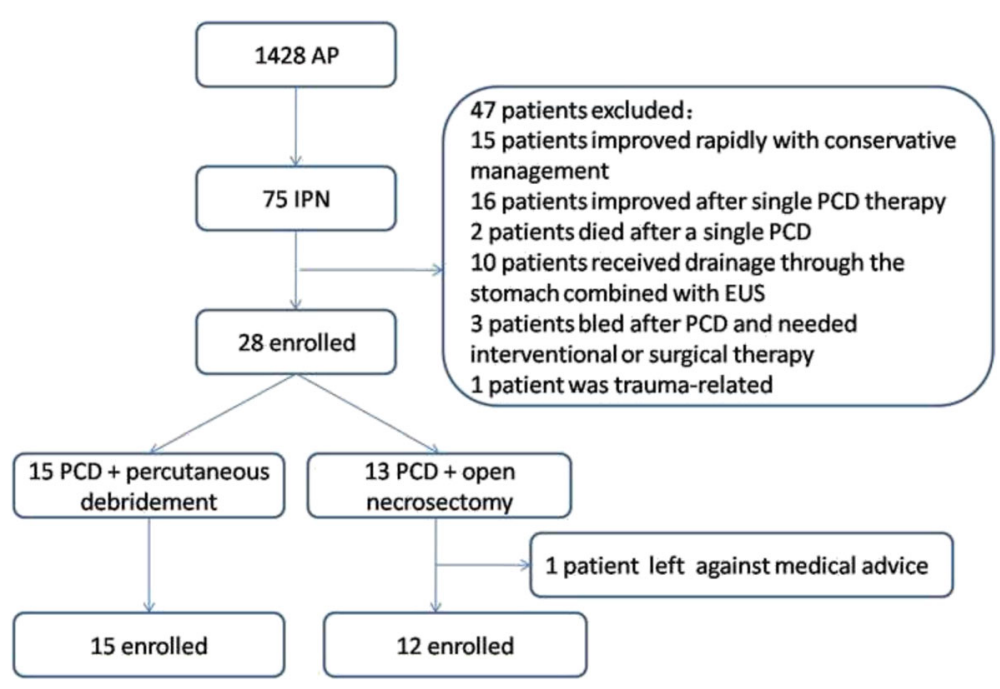

Fig. 1 Flow chart

its body. One end of the catheter is open; the other end is closed. Two tubes are inserted through the open end, one for irrigation and the other one for drainage. We call them inlet catheter and aspirator catheter respectively. The inlet catheter is longer than aspirator catheter. See Fig. 2c)After 1-2 weeks of lavage, the patients in the

Table 1 Baseline characteristics

\begin{tabular}{|c|c|c|c|}
\hline Item & $\begin{array}{l}\text { PCD + open } \\
\text { necrosectomy } \\
(n=12)\end{array}$ & $\begin{array}{l}\text { PCD+ percutaneous } \\
\text { debridement } \\
(n=15)\end{array}$ & $P$ value \\
\hline Age, median (IQR), year & $47(36-57)$ & $54(48-59)$ & 0.23 \\
\hline Male (\%) & $11(92 \%)$ & $10(67 \%)$ & 0.18 \\
\hline Pathogenesis (\%) & & & 0.03 \\
\hline Biliary & $4(33 \%)$ & $11(73 \%)$ & \\
\hline Hypertriglyceridemia & $5(42 \%)$ & $4(27 \%)$ & \\
\hline Other ${ }^{a}$ & $3(25 \%)$ & 0 & \\
\hline BMI, median (IQR) & $24(22-25)$ & $24(23-27)$ & 0.50 \\
\hline \multicolumn{4}{|l|}{ Severity } \\
\hline $\begin{array}{l}\text { APACHE score, } \\
\text { median (IQR) }\end{array}$ & $11(10-12)$ & $9(7-12)$ & 0.18 \\
\hline CRP, median (IQR), mg/L & $217(156-294)$ & $182(143-293)$ & 0.67 \\
\hline CTSI score, median (IQR) & $10(8-10)$ & $10(8-10)$ & 0.73 \\
\hline Ranson score & $2(2-3)$ & $3(1-3)$ & 0.72 \\
\hline Necrotic lesions & & & 0.22 \\
\hline $\begin{array}{l}\text { Pancreatic head, } \\
\text { body, and tail }\end{array}$ & $8(66 \%)$ & $7(47 \%)$ & \\
\hline Pancreatic body and tail & $2(17 \%)$ & $7(47 \%)$ & \\
\hline Pancreatic head & $2(17 \%)$ & $1(6 \%)$ & \\
\hline
\end{tabular}

$P C D$ percutaneous catheter drainage, $B M I$ body mass index, $I Q R$ inter-quartile range, CRP C-reactive protein, APACHE Acute Physiology and Chronic Health Evaluation, CTSI Balthazar CT severity index

ancluding alcoholic and idiopathic experimental group underwent percutaneous flexible endoscopic debridement (Host Olympus 260, gastroscope GIF-Q260J, diameter $9.9 \mathrm{~mm}, 3.2 \mathrm{~mm}$ work channel, UCR carbon dioxide air pump, OFP injection pumps, attachment Olympus hemostatic forceps FD-410QR, and spiral mesh MWB-2X4 and MWB-3X6 from COOK), while the patients in the control group underwent open necrosectomy (Figs. 2 and 3, Video 1-2). The primary endpoint was the composite end point of major complications or death [13]. The secondary endpoint was composed of death rate, major complication rate, postoperative ICU admission time, and hospital stay. The main complications included new-onset organ failure, multiple-organ failure, intestinal fistula, intra-abdominal bleeding, stress ulcer with bleeding, etc. (Table 2).

\section{Open necrosectomy}

The open necrosectomy, consisted of a laparotomy through bilateral subcostal incisions. After blunt removal of all necrotic tissue, two large-bore drains for postoperative lavage were inserted, and the abdomen was closed.

\section{Statistical analysis}

SPSS 18.0 software was applied for statistical analysis. Measurement data was presented as median and interquartile range (IQR). T test was performed upon normal distribution, while Mann-Whitney $U$ test was performed upon abnormal distribution. Enumeration data was depicted in frequency, and the differences between groups were compared by relative risk (RR), $95 \%$ confidence interval, and chi-square test. Fisher's exact test was used with reference of likelihood ratio chi-square. A $P<0.05$ was considered as statistical significant. 

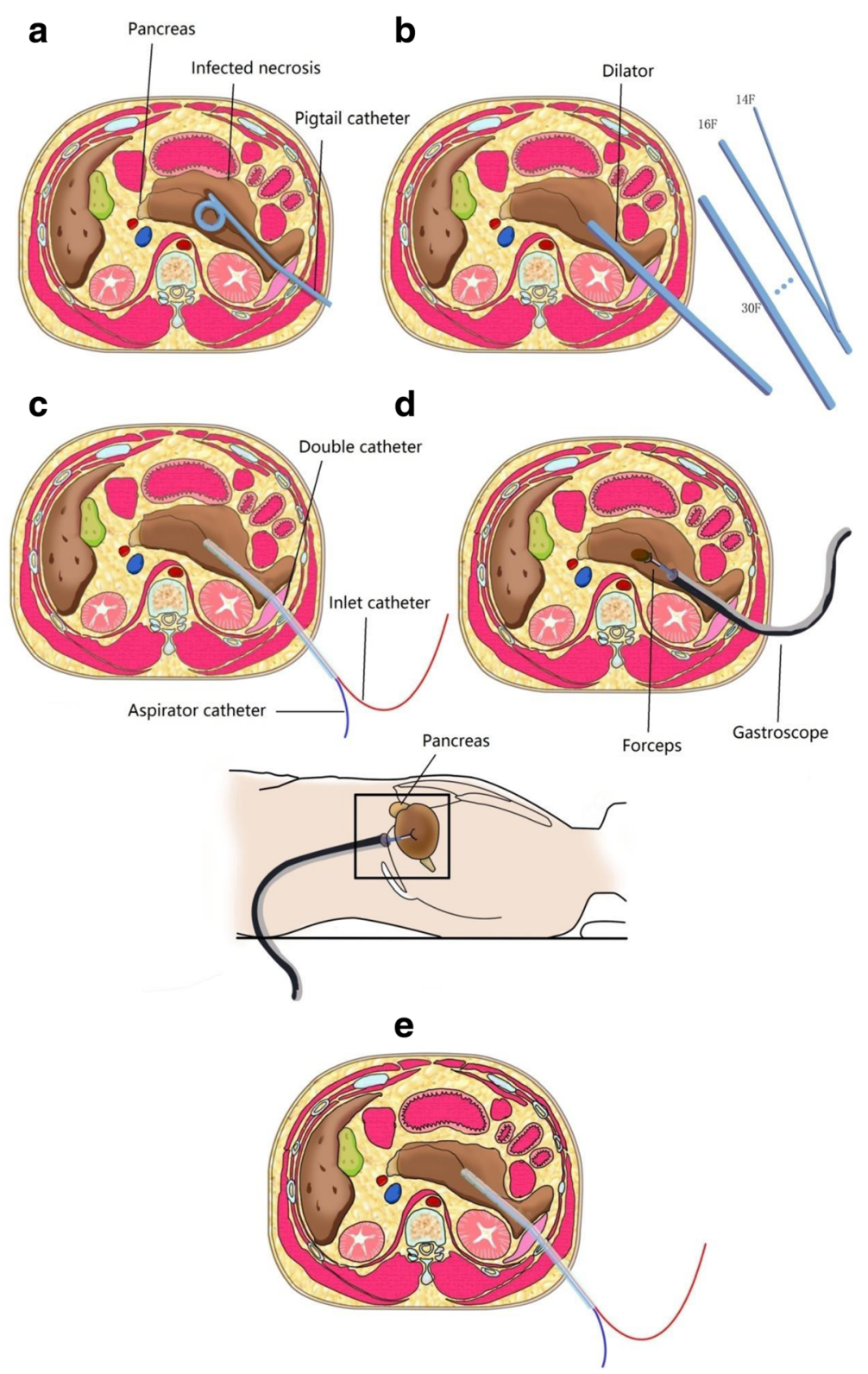

Fig. 2 Double-catheter lavage in combination with gastroscopic debridement treatment: a A percutaneous 8 to14 French pigtail catheter is placed in the peripancreatic collection under guidance of $\mathrm{CT}$ or ultrasound; $\mathbf{b}-\mathbf{c}$ A double catheter is placed for continuous irrigation and drainage after the sinus tract was expanded using 14-30Fr dilators; d Gastroscopic debridement: the necrosis is removed under direct vision with a long grasping forceps; e The double catheter is placed back for continuous irrigation and drainage. The images are designed and drawn by ourselves

\section{Results}

As shown in Table 3, The composite primary end point of major complications or death occurred in 11 of 12 patients after open necrosectomy (92\%) and in 8 of 15 patients after percutaneous debridement $(53 \%)(\mathrm{RR}=1.71$, 95\% $\mathrm{CI}=1.04-2.84)(P=0.04)$. For the secondary endpoints, the new organ failure rate was lower in the experimental group (13\%) compared to the control group (58\%)
$(P<0.05)$. Although other major complications including multiple organ failure, intestinal fistula, intra-abdominal bleeding, and stress ulcer with bleeding showed no statistical differences between two groups, their incidences trended lower in the experimental group. This difference was mainly driven by the occurrence of organ failure.

Although no statistical difference was observed in mortality between two groups $(P=0.19)$, two patients 

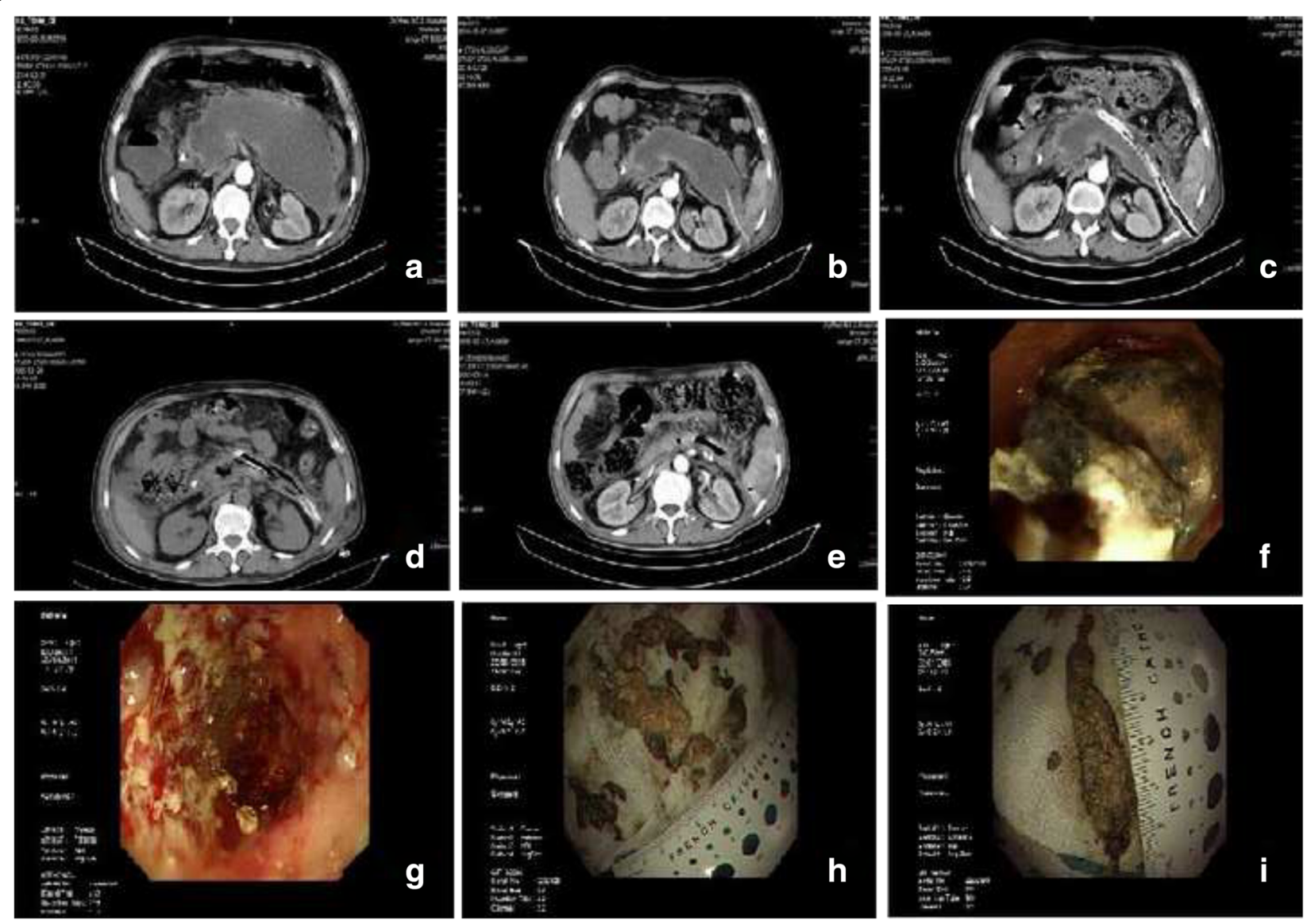

Fig. 3 Double-catheter lavage in combination with gastroscopic debridement. a before percutaneous debridement. b PCD drainage tube placement. c double catheter placement. $\mathbf{d}$ after percutaneous debridement. e recovery phase. $\mathbf{f}$ before debridement. $\mathbf{g}$ after debridement. $\mathbf{h}$ and $\mathbf{i}$, necrotic tissue

died in the control group (17\%) because of multiple organ failure and acute respiratory failure, while none died in the experimental group.

The experimental group had a markedly shorter postoperative ICU admission time than the controls $(P=0.02)$. Ten patients were admitted to the ICU in the open necrosectomy group (83\%), while only six patients were admitted to the ICU in the experimental group $(40 \%)(\mathrm{P}=0.02)$. The median hospital stay in the experimental group (52, 41-61 days) was similar to that of the control group (62, 4073 days).

Table 2 Definitions of major complication

\begin{tabular}{|c|c|c|}
\hline Major complication & Definition & Comment \\
\hline New-onset organ failure & $\begin{array}{l}\text { New-onset failure (i.e., not present at any time in the } 24 \mathrm{~h} \text { before first intervention); } \\
\text { Multiple-organ failure: failure of two or more organs at the same time. }\end{array}$ & \\
\hline Organ failure & & Adapted from Bradley [24] \\
\hline Pulmonary failure & $\mathrm{PaO} 2<60 \mathrm{mmHg}$, despite $\mathrm{FIO}$ of 0.30, or need for mechanical ventilation. & \\
\hline Circulatory failure & $\begin{array}{l}\text { Circulatory systolic blood pressure }<90 \mathrm{mmHg} \text {, despite adequate fluid resuscitation, } \\
\text { or need for inotropic catecholamine support. }\end{array}$ & \\
\hline Renal failure & Creatinine level > $177 \mu \mathrm{mol} / /$ after rehydration or new need for hemofiltration or hemodialysis. & \\
\hline Systemic complication & & Adapted from Bradley \\
\hline Gastrointestinal bleeding & $>500 \mathrm{ml}$ of blood/24 h & \\
\hline Intra-abdominal bleeding & Requiring surgical, radiologic, or endoscopic intervention. & \\
\hline Intestinal fistula & $\begin{array}{l}\text { Secretion of fecal material from a percutaneous drain or inflow into the necrotic cavity, } \\
\text { either from small or large bowel; confirmed by endscopy, imaging or during surgery. }\end{array}$ & \\
\hline
\end{tabular}


Table 3 Primary and secondary end points

\begin{tabular}{|c|c|c|c|c|}
\hline Outcome & $\begin{array}{l}\text { Open necrosectomy } \\
\text { after } \operatorname{PCD}(n=12)\end{array}$ & $\begin{array}{l}\text { Percutaneous debridement } \\
\text { after PCD } \\
(n=15)\end{array}$ & $\begin{array}{l}\text { Risk ratio } \\
(95 \% \mathrm{Cl})\end{array}$ & $P$ value \\
\hline $\begin{array}{l}\text { Primary composite end point: major complications } \\
\text { or death - no. }(\%)^{\mathrm{a}}\end{array}$ & $11(92 \%)$ & $8(53 \%)$ & $1.71(1.04-2.84)$ & 0.04 \\
\hline \multicolumn{5}{|l|}{ Secondary end points } \\
\hline \multicolumn{5}{|l|}{ Major complication - no. (\%) } \\
\hline New-onset organ failure & $7(58 \%)$ & $2(13 \%)$ & $4.38(1.11-17.32)$ & 0.04 \\
\hline Multiple-organ failure & $3(25 \%)$ & 0 & & 0.08 \\
\hline Intestinal fistula & $6(50 \%)$ & $7(47 \%)$ & $1.07(0.49-2.34)$ & 0.86 \\
\hline Intra-abdominal bleeding & $3(25 \%)$ & $1(7 \%)$ & $3.75(0.45-31.62)$ & 0.29 \\
\hline Stress ulcer with bleeding & $2(17 \%)$ & 0 & & 0.19 \\
\hline \multicolumn{5}{|l|}{ Other outcome } \\
\hline Intestinal obstruction & $2(17 \%)$ & 0 & & 0.19 \\
\hline Cerebral infarction & $1(8 \%)$ & 0 & & 0.44 \\
\hline Arrhythmia & 0 & $1(7 \%)$ & & 0.27 \\
\hline Death - no. (\%) & $2(17 \%)$ & 0 & & 0.19 \\
\hline Postoperative ICU admission time & & & & 0.02 \\
\hline Median & 17 & 0 & & \\
\hline IQR & $7-35$ & $0-9$ & & \\
\hline Days in hospital & & & & 0.25 \\
\hline Median & 62 & 52 & & \\
\hline IQR & $40-73$ & $41-60$ & & \\
\hline
\end{tabular}

${ }^{a}$ Multiple events in the same patient were considered as one end point

\section{Discussion}

IPN is one of the leading causes of death in AP. Timely diagnosis and effective treatment for IPN is of great significance to improve the prognosis. In the last 30 years, open necrosectomy has become the gold standard for IPN [2]; however, because the high short-term and longterm complication and fatality rate, minimally invasive techniques, especially the Minimally Invasive Step-up Approach [11], have been introduced in recent years. Acute pancreatitis treatment guidelines published by the American Gastroenterological Association in 2013 recommended that debridement of necrotic tissue be delayed for 4 weeks or later untill the necrotic area is enveloped by a fibrous wall to form WON, which can reduce bleeding and avoid damaging normal pancreatic tissue. Therefore, minimally invasive treatments could be applied first, and the endoscopic or open necrosectomy could be considered unless drainage fails [14]. Zerem E, et al. [15] retrospectively analyzed the outcome of 86 IPN patients managed by Minimally Invasive Stepup Approach, and found that the method was safe and effective, and PCD can allow most patients to avoid surgery. PCD is the minimally invasive method firstly used in the treatment of infectious pancreatitis. Though it exhibited high success rate in treating intra-abdominal abscesses and pancreatic pseudocysts, PCD is still controversial in IPN because of its inability to remove necrotic tissue fragments $[16,17]$.

A multicenter retrospective study in 2009 revealed that endoscopic transgastric necrosectomy had long-term effectiveness. The initial treatment success rate in 93 IPN patients who underwent endoscopic transgastric necrosectomy was $80 \%$.The complication rate within 30 days was $26 \%$, the mortality rate was $7.5 \%$, and the long-term success rate after an average follow-up of 43 months was $68 \%$ [18]. Similarly, another multicenter retrospective study enrolled 104 IPN patients who underwent endoscopic transgastric necrosectomy and showed a success rate of $91 \%$, a complication rate at $14 \%$, and $5 \%$ mortality [19]. Compared with open necrosectomy, endoscopic transgastric necrosectomy was more efficacious with lower morbidity and mortality. A randomized, controlled study in 2012 likewise demonstrated that endoscopic transgastric necrosectomy was associated with lower mortality ( $10 \%$ vs $40 \%)$, a lower new multiple organ failure rate $(0 \%$ vs $50 \%)$, and lower pancreatic fistula rate (10\% vs $70 \%)$ as compared to open necrosectomy [20].

Despite the success of endoscopic transgastricnecrosectomy, in the cases after the PCD treatment failure, percutaneous endoscopic debridement was more convenient 
than endoscopic transgastric necrosectomy. Firstly, endoscopic transgastric necrosectomy requires complex gastric or duodenal puncture and fenestration, while percutaneous endoscopic debridement can use the established drainage channel for exploration and further necrotic tissue removal with no need of advanced endoscopist. Secondly, the former requires general anesthesia, leading to longer procedure times and higher costs, whereas the latter can be accomplished with moderate sedation. Finally, the condition of endoscopic transgastric necrosectomy is limited to necrotic areas adjacent to the stomach or duodenum, while percutaneous endoscopic debridement can reach farther necrotic lesions in the abdominal cavity.

Though percutaneous endoscopic debridement is safe and effective, it still lacks supporting evidence at present. A large single center study in 2016 reported its success rate in 12 patients as high as $92 \%$, a complication rate of $8 \%$, and no procedure-related deaths [21]. Another multicenter study in India also confirmed the safety and efficiency of percutaneous endoscopic debridement. Among 15 IPN patients who underwent endoscopic percutaneous debridement, 14 cases improved, two cases exhibited complications (self-limited bleeding and pancreatic fistula), and there was one fatality [22].

This current study found that: (1) No air embolism occurred in the experimental group. It may be related to stable antrum and gap between sinus tract and endoscopy in percutaneous debridement process, which made the necrotic cavity connected to the outside, declining cavity pressure. In addition, Carbon dioxide is pumped in to expand the space for the instrument and prevent the occurrence of air embolism. (2) Fewer concurrent bleeding, which may be associated with waterflood pump irrigation and avoid of strong clearance of the lesion tissue adhere to the wall. (3) No pancreatic fistula occurred, as most patients with intestinal fistula can be self-healed by inserting thinner rubber drainage. (4) Fewer times of percutaneous debridement (1-2), but longer time duration of each drainage (about $2 \mathrm{~h}$ ). (5) Our flexible endoscope can be inserted into the anfractuous sinus tract to remove more necrosis under direct vision.

To sum up, PCD is characterized as simple, convenient, larger approach choice, early application to reduce the necrotic cavity pressure and prevent bacterial toxins absorbed into the blood, and improving the systemic inflammatory response syndrome and sepsis [23]. Gastroscope could be applied through the established drainage channel for exploration and removal of necrotic tissue once PCD failure. Follow the principle of minimally invasive step-up approach, this study adopted double catheter lavage in combination with percutaneous flexible endoscopic debridement for IPN treatment. It can reduce the primary endpoint indicators (the composite end point of major complications or death), new organ failure rate, and postoperative ICU admission time compared with open necrosectomy, revealing its safety and effectiveness. Moreover, endoscopic transgastric necrosectomy was preferred when the necrotic lesions was adjacent to stomach or duodenum, which can reduce intestinal canal and vascular damage. Surgical treatment should be chose according to the clinical characteristics and lesions anatomical position. There are many drawbacks in this study: (1) It was a retrospective cohort study in small scale. (2) The constituent ratio of causes was different and there was one patient automatic discharge. (3) The lack of follow-up data. Percutaneous debridement is an effective method for IPN, future large scaled randomized controlled study should be carried out to provide the evidence of evidence-based medicine.

\section{Conclusions}

Our data suggest that double-catheter lavage in combination with percutaneous flexible endoscopic debridement may show superior effectiveness, safety, and convenience in patients with IPN after PCD failure as compared to open necrosectomy. Although the series is small, there is merit in replication of the finding that minimal access approaches confer advantages over the open approach. Our study may provide a new idea for treatment of IPN.

\section{Additional files}

Additional file 1: Video 1. Percutaneous flexible endoscopic debridement, the operation process of double-catheter lavage in combination with percutaneous flexible endoscopic debridement treatment. (see Methods section in more detail). (AVI $317000 \mathrm{~kb}$ )

Additional file 2: Video 2. Details on the step-up approach, the operation process of double-catheter lavage in combination with percutaneous flexible endoscopic debridement treatment. (see methods section in more detail). (AVI $521000 \mathrm{~kb})$

\section{Abbreviations}

ANC: Acute necrotic collection; AP: Acute pancreatitis; EUS: Endoscopic ultrasonography; IPN: Infected pancreatic necrosis; IQR: Interquartile range; PCD: Percutaneous catheter drainage; RR: Relative risk; WON: Walled-off necrosis

Acknowledgments

We thank Professor Michael Pezzone for enlightening discussions.

Funding

This work was supported by the National Natural Science Foundation of China (project number: 81,560,112).

Availability of data and materials

In attempt to preserve the privacy of patients, clinical data of patients will not be shared; data can be available from authors upon request.

\section{Fund project}

National Natural Science Foundation of China (project number: 81,560,112).

\section{Authors' contributions}

PL: study concept and design, acquisition of data, analysis and interpretation of data, critical revision of the manuscript for important intellectual content; JS: acquisition of data, analysis and interpretation of data, drafting of the manuscript, critical revision of the manuscript for important intellectual content; HK: acquisition of data, analysis and interpretation of data, drafting 
of the manuscript; NL: analysis, critical revision of the manuscript for important intellectual content; YiZ: analysis, critical revision of the manuscript for important intellectual content; $\mathrm{HZ}$ : acquisition of data, critical revision of the manuscript for important intellectual content; YoZ: acquisition of data, critical revision of the manuscript for important intellectual content; LX: acquisition of data, critical revision of the manuscript for important intellectual content; WH: interpretation of data, drafting of the manuscript; $J \mathrm{~L}$ : interpretation of data, drafting of the manuscript; $\mathrm{XH}$ : analysis, interpretation of data; YL: analysis, interpretation of data; All authors approved the final version of the article, including the authorship.

\section{Ethics approval and consent to participate}

The Medical Ethics Committee of the First Affiliated Hospital of Nanchang University approved the protocol(Ethical approval No. 2013020). Each participant provided written informed consent to be included in the study.

\section{Consent for publication}

Not applicable.

\section{Competing interests}

The authors declare that they have no competing interests.

\section{Publisher's Note}

Springer Nature remains neutral with regard to jurisdictional claims in published maps and institutional affiliations.

Received: 22 April 2017 Accepted: 28 November 2017

Published online: 08 December 2017

\section{References}

1. Working Group IAP/APA Acute Pancreatitis Guidelines. IAP/APA evidencebased guidelines for the management of acute pancreatitis. Pancreatology 2013;13:e1-15

2. Uhl W, Warshaw A, Imrie C, Bassi C, McKay CJ, Lankisch PG, et al. IAP guidelines for the surgical Management of Acute Pancreatitis. Pancreatology. 2002:2:565-73.

3. Petrov MS, Shanbhag S, Chakraborty M, Phillips AR, Windsor JA. Organ failure and infection of pancreatic necrosis as determinants of mortality in patients with acute pancreatitis. Gastroenterology. 2010;139:813-20

4. Rodriguez JR, Razo AO, Targarona J, Thayer SP, Rattner DW, Warshaw AL, et al. Debridement and closed packing for sterile or infected necrotizing pancreatitis: insights into indications and outcomes in 167 patients. Ann Surg. 2008:247:294-9.

5. Besselink MG, van Santvoort HC, Buskens E, Boermeester MA, van Goor H, Timmerman HM, et al. Probiotic prophylaxis in predicted severe acute pancreatitis: a randomised, double-blind, placebo-controlled trial. Lancet. 2008:371:651-9.

6. Raraty MG, Halloran CM, Dodd S, Ghaneh P, Connor S, Evans J, et al. Minimal access retroperitoneal pancreatic necrosectomy: improvement in morbidity and mortality with a less invasive approach. Ann Surg. 2010;251:787-93

7. van Santvoort HC, Bakker OJ, Bollen TL, Besselink MG, Ahmed Ali U, Schrijver AM, et al. A conservative and minimally invasive approach to necrotizing pancreatitis improves outcome. Gastroenterology. 2011;141:1254-63.

8. Banks PA, Bollen TL, Dervenis C, Gooszen HG, Johnson CD, Sarr MG, et al. Classification of acute pancreatitis-2012: revision of the Atlanta classification and definitions by international consensus. Gut. 2013;62:102-11.

9. van Grinsven J, van Santvoort HC, Boermeester MA, Dejong $\mathrm{CH}$, van Eijck $\mathrm{CH}_{\text {, }}$ Fockens $P$, et al. Timing of catheter drainage in infected necrotizing pancreatitis. Nat Rev Gastroenterol Hepatol. 2016;13:306-12.

10. Wronski M, Cebulski W, Karkocha D, Slodkowski M, Wysocki L, Jankowski M, et al. Ultrasound-guided percutaneous drainage of infected pancreatic necrosis. Surg Endosc. 2013:27:2841-8.

11. van Santvoort HC, Besselink MG, Bakker OJ, Hofker HS, Boermeester MA,

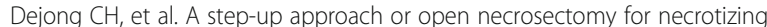
pancreatitis. N Engl J Med. 2010;362:1491-502.

12. Horvath K, Freeny P, Escallon J, Heagerty P, Comstock B, Glickerman DJ, et al. Safety and efficacy of video-assisted retroperitoneal debridement for infected pancreatic collections: a multicenter, prospective, single-arm phase 2 study. Arch Surg. 2010;145:817-25.

13. van Brunschot S, van Grinsven J, Voermans RP, Bakker OJ, Besselink MG, Boermeester MA, et al. Transluminal endoscopic step-up approach versus minimally invasive surgical step-up approach in patients with infected necrotising pancreatitis (TENSION trial): design and rationale of a randomised controlled multicenter trial [ISRCTN09186711]. BMC Gastroenterol. 2013;13:161.

14. Tenner S, Baillie J, DeWitt J, Vege SS. American College of Gastroenterology guideline: management of acute pancreatitis. Am J Gastroenterol. 2013:108:1400-15. 16

15. Zerem E, Imamovic G, Susic A, Haracic B. Step-up approach to infected necrotising pancreatitis: a 20-year experience of percutaneous drainage in a single centre. Dig Liver Dis. 2011;43:478-83.

16. Delattre JF, Levy Chazal N, Lubrano D, Flament JB. Percutaneous ultrasoundguided drainage in the surgical treatment of acute severe pancreatitis. Ann Chir. 2004;129:497-502.

17. Navalho M, Pires F, Duarte A, Goncalves A, Alexandrino P, Tavora I. Percutaneous drainage of infected pancreatic fluid collections in critically ill patients: correlation with C-reactive protein values. Clin Imaging. 2006;30:114-9.

18. Seifert H, Biermer M, Schmitt W, Jurgensen C, Will U, Gerlach R, et al. Transluminal endoscopic necrosectomy after acute pancreatitis: a multicentre study with long-term follow-up (the GEPARD study). Gut. 2009;58:1260-6

19. Gardner TB, Coelho-Prabhu N, Gordon SR, Gelrud A, Maple JT, Papachristou GI, et al. Direct endoscopic necrosectomy for the treatment of walled-off pancreatic necrosis: results from a multicenter U.S. series. Gastrointest Endosc. 2011;73:718-26.

20. Bakker OJ, van Santvoort HC, van Brunschot S, Geskus RB, Besselink MG, Bollen TL, et al. Endoscopic transgastric vs surgical necrosectomy for infected necrotizing pancreatitis: a randomized trial. JAMA. 2012;307:1053-61.

21. Mathers B, Moyer M, Mathew A, Dye C, Levenick J, Gusani N, et al. Percutaneous debridement and washout of walled-off abdominal abscess and necrosis using flexible endoscopy: a large single-center experience. Endosc Int Open. 2016;4:E102-6.

22. Dhingra R, Srivastava S, Behra S, Vadiraj PK, Venuthurimilli A, Shalimar, et al. Single or multiport percutaneous endoscopic necrosectomy performed with the patient under conscious sedation is a safe and effective treatment for infected pancreatic necrosis (with video). Gastrointest Endosc. 2015;81:351-9.

23. Navaneethan U, Vege SS, Chari ST, Baron TH. Minimally invasive techniques in pancreatic necrosis. Pancreas. 2009;38:867-75.

24. Bradley EL III. A clinically based classification system for acute pancreatitis. Summary of the International Symposium on Acute Pancreatitis, Atlanta, Ga, September 11 through 13, 1992. Arch Surg. 1993;128:586-90.

\section{Submit your next manuscript to BioMed Central and we will help you at every step:}

- We accept pre-submission inquiries

- Our selector tool helps you to find the most relevant journal

- We provide round the clock customer support

- Convenient online submission

- Thorough peer review

- Inclusion in PubMed and all major indexing services

- Maximum visibility for your research

Submit your manuscript at www.biomedcentral.com/submit
Biomed Central 